International Symposium on the Analytic Hierarchy Process, Honolulu, Hawaii, July 7-10, 2005.

\title{
USING ANP IN THE NON-PROFIT SECTOR: SELECTING A CONGRESS SITE AND PREDICTING CONFERENCE ATTENDANCE ${ }^{1}$
}

\author{
Enrique $\mathrm{Mu}$ \\ University of Pittsburgh \\ enmu@katz.pitt.edu
}

Keywords: ANP, non-profit, predictive models, site selection

\begin{abstract}
Summary
Non-profit organizations operate with more tight budgets and restrictions than their private counterparts. There is always a risk that a wrong decision may have catastrophic effects for the organization. Also, decisions made by non-profit managers tend to be highly scrutinized by their constituents in terms of consistency with the organizational mission, objectives, etc. This creates the need for managers, to use a methodology that not only assists in their decision-making process but that also allows them to explain the decision criteria to the organizational stakeholders. This paper reports an on-going application of the Analytic Network Process (ANP) in the context of one such organization: The Latin American Studies Association (LASA). LASA organizes a large international conference every eighteen months and need to estimate conference attendance in advance (for logistic purposes) as well as selecting a Latin American city where the combination of hotel infrastructure, conference costs, and so on, makes it a sound financial choice.

In this paper, ANP will be used to first, create a model to predict the relative number of attendees to the forthcoming 2009 LASA international conference; and second, to create a Benefit-Cost-Risk (BCR) model that will provide a framework to select the most suitable Latin American city as the conference site. This paper shows how the combination of these two ANP models, for prediction and selection, can be used together for effective decision-making in the non-profit sector. From a practical point of view, these two models will allow LASA top managers, to select a conference site for their forthcoming March 2009 International LASA congress in a rational, consistent way, based on both the expected number of attendees and organizational objectives. Also, using ANP methodology, LASA managers will be able to explain to interested constituents, the criteria used in the selection process.
\end{abstract}

\footnotetext{
${ }^{1}$ The author would like to thank Milagros Pereyra, LASA's executive director, and Maria Cecilia Dancisin, LASA's congress coordinator, whose knowledgeable and enthusiastic collaboration has made this paper possible. Also, I am deeply grateful to Rozann Saaty, from the Creative Decisions Foundation, who assisted me with some of the Super Decision software intricacies.
} 


\section{Introduction.}

Non-profit organizations work with tighter restrictions in terms of resources and regulations. Typically, they are understaffed and since they are highly dependent on grants and voluntary contributions, they must find ways to optimize the use of their resources. Also, all their decisions must be quite transparent to their constituents due to the public nature of their activities. Because of this, non-profit managers may benefit of tools to assist them in the optimal allocation of their limited resources, and which may also allow them to explain to their stakeholders the decision criteria. This paper discusses the on-going application of the analytic network process (ANP), a multi-criteria approach for decision making that allows mixing tangible and intangible objectives (Sarkis and Sanadarraj 2002), to the selection of a host city for a large international professional conference.

The motivation for our study was the problem encountered by the Latin American Studies Association (LASA), the world's largest professional association for Latin American studies ${ }^{2}$. This association counts with more than 5,000 members worldwide and organizes a large international conference every 18 months. For many years, these conferences have taken place in U.S. cities; however, there have been increasing pressure from LASA members to have conferences outside the U.S., mainly in places related to LASA's areas of study. More specifically, LASA's executive committee has mandated that the LASA 2009 conference should take place in a Latin American city. This paper reports the application of ANP to develop models to assist LASA's management in first, predicting attendance to the conference -based on city characteristics and members' preferences- and second, to select -using a benefit/cost/risk- analysis- the most suitable city for LASA's 2009 conference. In the next section, we review the characteristics of LASA's conferences and the specific challenges due to the decision to select conference sites in Latin America. Next, we will briefly review the basic characteristics of the ANP methodology and why it is particularly suitable for this problem. After this, the proposed ANP models for prediction and selection will be discussed. Finally, overall results are obtained and discussed.

\section{Problem Statement.}

LASA's conference is considered one of the biggest professional gatherings of their type, with an attendance of thousands of their members and presentations of about 3,000 professional papers. Because of this, the logistics involved in the organization of the conference is gigantic. For the same reason, LASA's hotel contracts are usually made five or more years in advance. The number of hotel rooms contracted in advance is made based on a guess of conference attendees. A successful conference is one where a large number of member attendance, and where the number of rooms contracted in advance by LASA matches approximately the number of attendees (to avoid financial hardships). At first, it would seem that LASA could opt to be very conservative in the number of precontracted rooms. However, due to the culture in the organization, and uncertainty in the regions where the participants come from, a very large number of members sign for the conference on site. Should LASA fell short in the number of rooms reserved, a large number of participant members could have lodging problems with the subsequent confusion and complaints.

LASA's executive committee has mandated that the March 2009 conference should take place in a Latin American city. Since this is the first time, for practical purposes, the conference will take place outside the U.S, the familiar patterns and guesses are not applicable anymore. This imposes two decision-making challenges to LASA management: first, it is important to estimate expected attendance to the conference (to contract out rooms in advance), and second, it is important to select the most suitable Latin American city for the conference. This second task is particularly important in the case of conferences outside the U.S. Due to its magnitude and prestige, some Latin American cities would be interested in hosting the conference and lobby the different members of LASA's executive

\footnotetext{
${ }^{2}$ All information about LASA has been obtained from direct interview with LASA management team. This author also attended LASA meetings (two of them outside the U.S.) to get more first hand experience with the conference and its planning.
} 
committee for that purpose. Therefore, granting the hosting rights to one city over the other needs to be fully transparent to avoid any hint of unfairness or bias. Also, LASA's management must make sure that the costs associated with organizing the conference, such as conference rooms, audio visual equipment, etc, are reasonable and within budget. In fact, the number of attendees should finance the direct costs associated with the conference. This could lead to situation where a city could be very attractive for the LASA members but inconvenient for the conference organizers. On top of this, there are risks associated with the political and economical instability associate to the Latin American region that must also be taken into account. For all these reasons, a multi-criteria decision making methodology such as ANP could assist LASA in tackling the problem of selecting a Latin American city to host the 2009 LASA conference.

\section{The Use of ANP.}

ANP is a generalization of the Analytic Hierarchy Process (AHP) developed by Thomas Saaty (2000). AHP allows the simultaneous inclusion of tangible and intangible criteria. AHP models a decision making problem using a framework that assumes a unidirectional hierarchical relationship among decision levels. The top element of the hierarchy is the goal for the decision model. The subsequent levels model the criteria, sub-criteria and alternatives. The hierarchy is basically a system where one group of entities influences another set of entities in another level of the hierarchy. The hierarchy decomposes from the general to the more specific attributes until a manageable level of decision criteria is reached. AHP has been applied to decision-making situations in both the private and public sector. AHP is straightforward and comprehensive which makes the decision evaluation easier to communicate to relevant stakeholders. It is also adaptable for both individual and group decision making. AHP is a suitable tool when optimization is not pursued, resources are not restricted, and interdependencies do not exist (Shang, Tjader and Ding 2004).

The ANP is a general form of the AHP (1990) that allows optimization and interdependency among the decision levels and elements. The general characteristics of ANP are: first, ANP does not require a rigid hierarchical structure; second, interdependencies among different clusters of elements or even among elements within the same cluster (intradependencies) are allowed; and third, the relative importance of each element and its impact on each other can be determined using a ratio scale similar to AHP. In summary, the ANP approach is capable of handling interdependence among elements by obtaining the composite weights through the development of a "supermatrix."

In a nutshell, the ANP process operates as follows: first, a model, which includes criteria grouped in clusters and dependency among the different elements in the network is developed. Second, pairwise comparison is made for the elements of the network and this leads to an unweighted supermatrix that contains the local priorities. Third, clusters are compared pairwise to determine their relative importance and the result is a cluster weights matrix. This cluster weights matrix is used to weight the unweighted supermatrix, resulting in a stochastic weighted supermatrix that combines the local priorities of the elements weighted by the corresponding cluster importance. To synthesize the network, the weighted supermatrix is raised to powers (multiplied times itself) until each column in the matrix is identical to the other columns (limit matrix). At this stage, any of the columns in the limit matrix provides the final priorities for all the elements, and in particular for the alternatives, in the network. The reader is referred to Saaty (2001) for further detail in the methodology.

ANP is a relatively new methodology that is still not well-known to the decision-making community (Meade and Preseley 2002; Sarkis and Sanadarraj 2002; Shang et al. 2004). Its application has been limited to academic settings (Garuti and Escudey 2005) and large scope projects (Shang et al. 2004). Furthermore, there are some concerns whether ANP is too complex to be used outside the academic decision-making community and by the average practitioner ${ }^{3}$. This paper contributes to the ANP literature twofold: first, it intends to dispel this concern through the application of relative novel methodology in a real setting; and second, shows how to combine ANP models for prediction and

\footnotetext{
${ }^{3}$ Concern expressed to this author in private conversation by an experienced commercial AHP practitioner.
} 
selection to tackle specific practical problems (predicting conference attendance and selecting a conference site). Next, we will develop the ANP model for the decision-making situation at hand.

\section{The Proposed ANP Models.}

As mentioned before, LASA needs to deal with two different problems. First, LASA needs to forecast the approximate number of attendees to each conference. Experience has shown that the characteristics of the city such as touristic interest, cost of living, etc; place an important role in the number of attendees. So, to forecast congress attendees, an ANP market share prediction model has been developed. Second, LASA needs to analyze and select a suitable Latin American city for the conference. Although potential number of attendees is an important factor, LASA management must take also into account costs related to organizing the conference in a given city. Some intangible factors such as political alignment with LASA's mission are also important. Based on this, an ANP benefit/cost/risk (BCR) model has been developed.

\subsection{Predicting attendees to the conference.}

To develop this model, we interviewed LASA managers and asked them, based on their experience from past conferences, what they considered to be the critical factors for LASA conference attendance. These factors were validated through interviews with other LASA members. All the different factors were initially compiled just as a long list and without paying attention to any overlapping or redundancy. After this, the factors were reviewed and categorized into the following clusters: costs, political/strategic factors, touristic activities, and risks. Costs are related to airline tickets ${ }^{4}$, hotel room, and per diem costs for the attendee. Travel appeal refers to the average travel time to the conference city, language attraction (e.g. Spanish), touristic activities, visa costs, and time of the year (for the conference). Political/strategic factors are constituted by the political and economical situation of the host country as well as the country alignment with LASA's mission. Risks for LASA members are those related to public safety in the host city. It was also estimated that some of these factors were interrelated. For example, the political situation of a country is usually influenced by the economic situation and viceversa. The resulting model is shown in Figure 1 (at this stage ignore the elements in the alternative cluster which will be explained later in this section).

\section{$<$ Insert Figure 1 here $>$}

After the initial model was completed, there was a meeting with LASA's management team and based on this, some adjustments to the model were made. Also, the description of each criterion and its impact on the decision to attend the conference was further discussed. Next, using pairwise comparison, the importance of the different factors (clusters) and specific criteria was determined. Table 1 summarizes the criteria, sub-criteria and their importance in conference attendance.

$<$ Insert Table 1>

Once the model was ready, one question in the mind of participants was: given two or three candidate cities, how well can this model predict conference attendance? To answer this question, the model was used to predict attendance to three LASA conferences for which participation data were available: the October 2004 conference in Las Vegas, the March 2003 conference in Dallas, and the forthcoming March 2006 conference in Puerto Rico ${ }^{5}$. The question was, if we would have used the

\footnotetext{
${ }^{4}$ For some factors such as cost of airline tickets, an average value was estimated, taking into account that more than $70 \%$ of conference attendees are U.S. based.

${ }^{5}$ LASA doesn't collect data about full attendance but about participation attendance; that is those members who will participate as presenters, panelists, etc. This is the target of interest for LASA management since hotel bookings are made based on these participants. For this reason, even though March 2006 conference in Puerto Rico has not taken place as of the writing of this paper, the number of congress participants (who need to commit several months in advance) is already known. In this paper, predicting conference attendance refers to predicting conference participants.
} 
developed model to predict relative attendance among these three conferences, what would the model have predicted? To test this, the three cities were included as alternatives in the model as shown in the cluster of alternatives in Figure 1. A pairwise judgment evaluation among the different elements was made to determine local priorities and obtain the unweighted supermatrix. Next, this matrix was weighted by the cluster weights matrix to obtain the weighted supermatrix which in turn was raised to powers to obtain the limit matrix with the final priorities. This process was made using Super Decisions software created by Saaty (2004) to alleviate the mathematical burden. The final priorities for the alternatives are shown in Table 2.

$<$ Insert Table 2 here $>$

The priorities from Table 2 can be used to predict conference attendance as shown in Table 3. It is worth clarifying the nominal and adjusted attendance figure for the Dallas conference shown in this Table. First of all, as mentioned earlier, LASA doesn't keep track of all congress attendants; only of congress participants; that is, those who will participate as presenters, panelists, or in any other role in the conference. It is rare for participants to cancel their attendance, unless unforeseen circumstances such as health problems arise. So, the nominal attendance figures shown in Table 3 correspond to this category. One important caveat is needed for the Dallas attendance. The March 2003 LASA conference in Dallas took place among political protests by some LASA members against the imminent Irak war. As a result 30 out of 200 members who were already scheduled to participate and had been given travel and expense grants by LASA, cancelled their participation as a form of protest against the war. Only those members who are receiving any kind of financial assistance from LASA are required to inform in writing about cancellation reasons; so it is reasonable to guess that a similar proportion of LASA members abstained from participating in the first place as a way of protest against the war. The Dallas conference took place in March 2003 when the U.S. invasion of Irak was imminent. We have assumed that the same percentage of people that abstained to participate among the participants with travel and expense grants $(30 / 200=15 \%)$, also abstained from participate among the members at large. For this reason, these cancellations were added to the number of Dallas nominal participants to obtain the value that would have constituted the "actual" conference participation ${ }^{6}$. It is possible to use the normalized final priorities calculated in the ANP model to predict attendance to the different conferences as shown in the 'predicted' conference attendance column. The variance between the prediction and the actual participation varies between $4.3 \%$ and $10.7 \%$, which is reasonable for LASA purposes ${ }^{7}$. Furthermore, it is possible to use the normalized priorities from Table 2 to calculate Saaty's compatibility index as shown in the Appendix. The result is a compatibility index of 1.00425 which is much less than 1.1, indicating a good degree of compatibility between the predicted and actual values.

$<$ Insert Table 3 here $>$

As of this writing, there are three candidate cities for the 2009 LASA conference. These cities are identified as city 1,2 , and 3 in this paper ${ }^{8}$. Our model is currently in use to predict relative conference attendance among these three cities. Once this is done, the actual expected participation number can be calculated by comparing the selected city ${ }^{9}$ against a city whose participation number has been fully established (e.g. Puerto Rico).

\footnotetext{
${ }^{6}$ When using the model to compare the relative preference of Dallas, Las Vegas, and Puerto Rico; the judgments were made assuming normal political situation in all three cases for comparison purposes. ${ }^{7}$ Further meetings with LASA management team to fine tune the model and to perform sensitivity analysis are still pending.

${ }^{8}$ City names are withheld since negotiations are still under way.

${ }^{9}$ It is important to remember that LASA management cannot select a conference city based only on expected participation, as will be seen in the next section. However, estimating participation size is important to contract hotel rooms in advance, among other logistic considerations.
} 


\subsection{Selecting a conference host city.}

As mentioned earlier, LASA management team must select a city to host the LASA conference, based not only in terms of attendance but also in terms of logistics, economic benefits, and political considerations. For example, it is too expensive to ship 3,000 or more program books and CDs overseas. It may be much more convenient to print the material in the host city. Is the task feasible at a reasonable price? Similarly, some city governments may be willing to sponsor the conference, providing publicity and official clout to the LASA conference. In other words, there are several factors that the LASA management team requires to consider in the analysis and selection of a conference site.

Again, a brain storming session took place with LASA top management and a list of the factors they considered important for the decision was elaborated. A cost-benefit analysis using ANP was proposed. For this purpose, the factors were categorized into three subnets: benefits, costs, and risks to be used in a BCR model, according to Saaty's (2001) framework. Any certain positive (negative) outcome was classified as benefit (cost). Any potential but uncertain negative outcome was classified as a risk. No opportunities were identified when preparing the model. Once the factors were categorized, a second meeting took place with LASA top management. The categories and factors were reviewed and the importance of each cluster with respect to the overall goal was assessed through a pairwise comparison. Similarly, the dependence and/or influence of one cluster over the other in each subnet was determined. The result was the model shown in Figures 2a-2d. Table 4 provides a summary of results for each of the synthesized subnets. The rightmost columns shows the calculated overall normalized priority using a multiplicative formula.

$<$ Insert Figure 2a-2d here $>$

$<$ Table 4>

Table 4 shows, we find that city 2 scores the highest in benefits while city 3 has the highest costs. Using the multiplicative formula $\mathrm{B} /\left(\mathrm{C}^{*} \mathrm{R}\right)$ is possible to determine that the highest overall priority corresponds to city 2. In summary, according to LASA objectives, city 2 is the most suitable one for the 2009 conference. Notice that in calculating the overall priority, it has been assumed that benefits, costs, and risks have the same weight, which is not necessarily true but a high risk adverse organization. However, it is possible to calculate the overall priority using a substractive formula of the form Nor (w1 x B - w2 x C - w3 x R) where w1, w2, and w3 are the desirable weights for benefits, costs, and risks and Nor $(*)$ stands for the normalized value of $(*)$. The Super Decision software allows computing the overall preference using a substractive formula and changing the weights of benefits, costs, and risks ${ }^{10}$.

\section{Summary and Conclusion.}

This paper explores the potential to apply, a relatively new decision-making methodology: the analytic network process (ANP), in the context of a small non-profit organization. This method has been found to be as straightforward and intuitive as its AHP predecessor. It offers, for a non-profit organization such as LASA, a transparent and systematic approach to make complex decisions that involve both tangible and intangible criteria which are not addressed by traditional mathematical programming methods.

10 As mentioned earlier, the comparison of alternatives are still pending to be reviewed since negotiations in these three cities are still under development. For this same reason, sensitivity analysis has not been performed yet. 


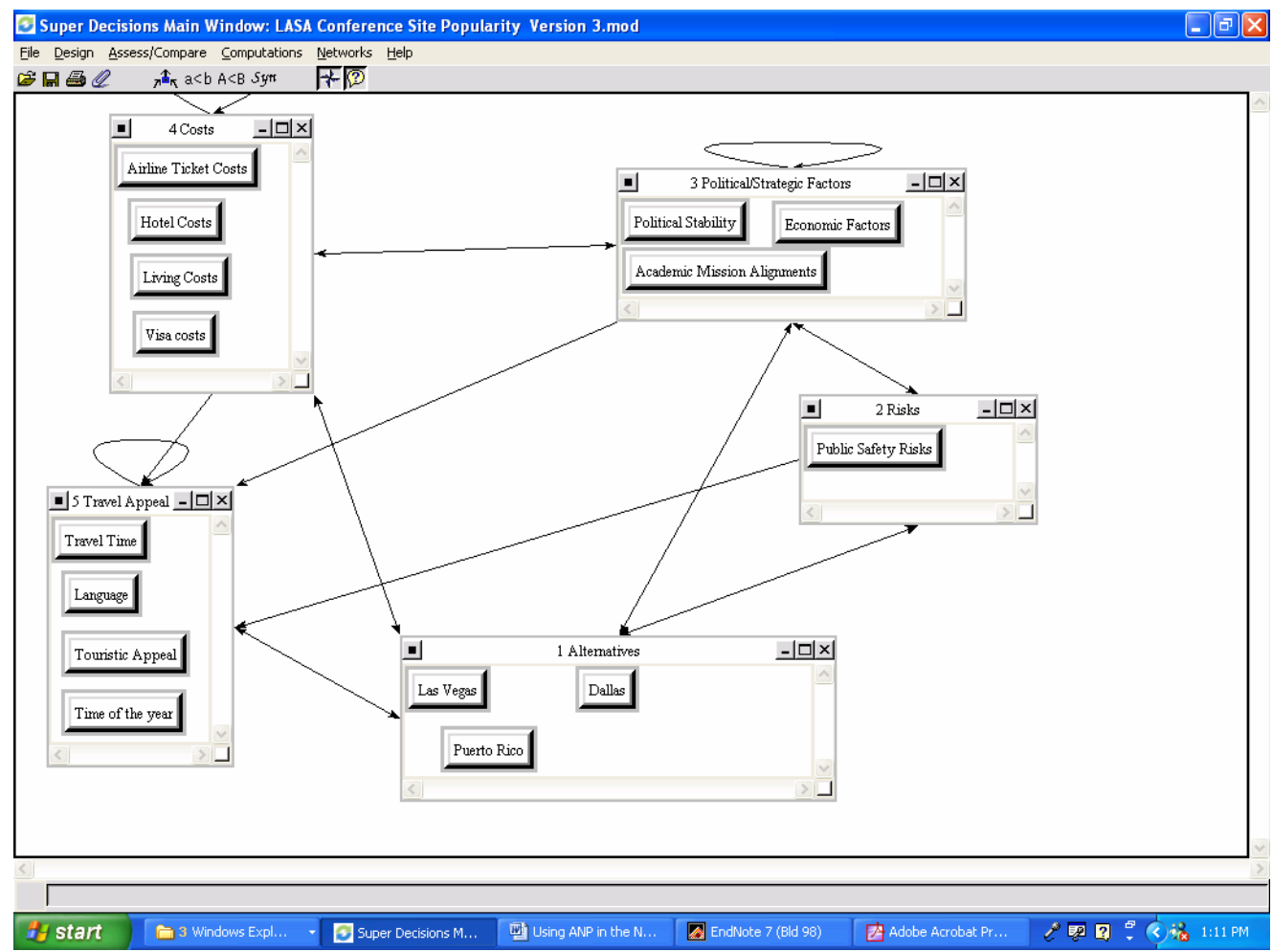

Figure 1 - Predicting Conference Attendance ANP Model. 


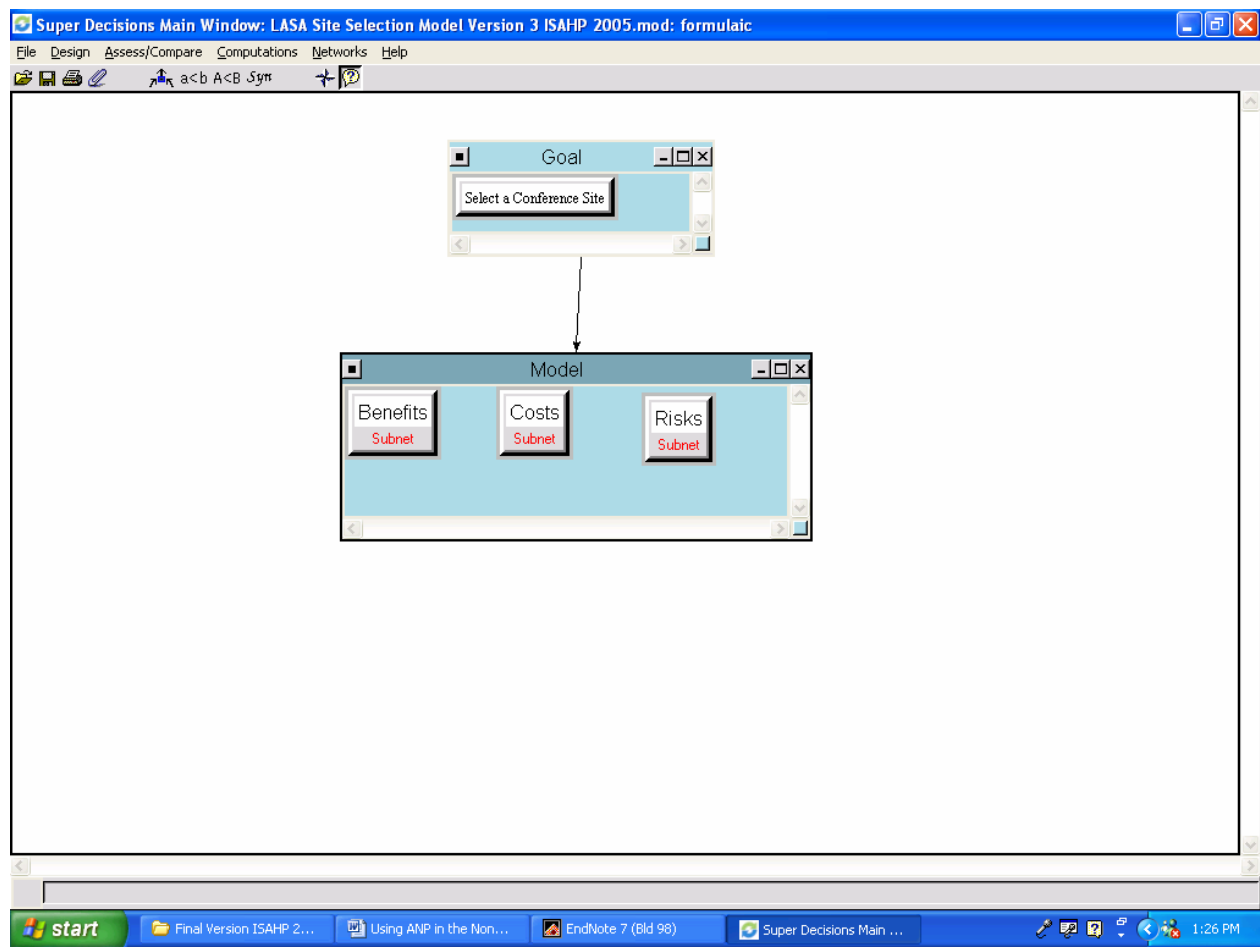

Figure 2 (a) - BCR Model for Conference Site Selection

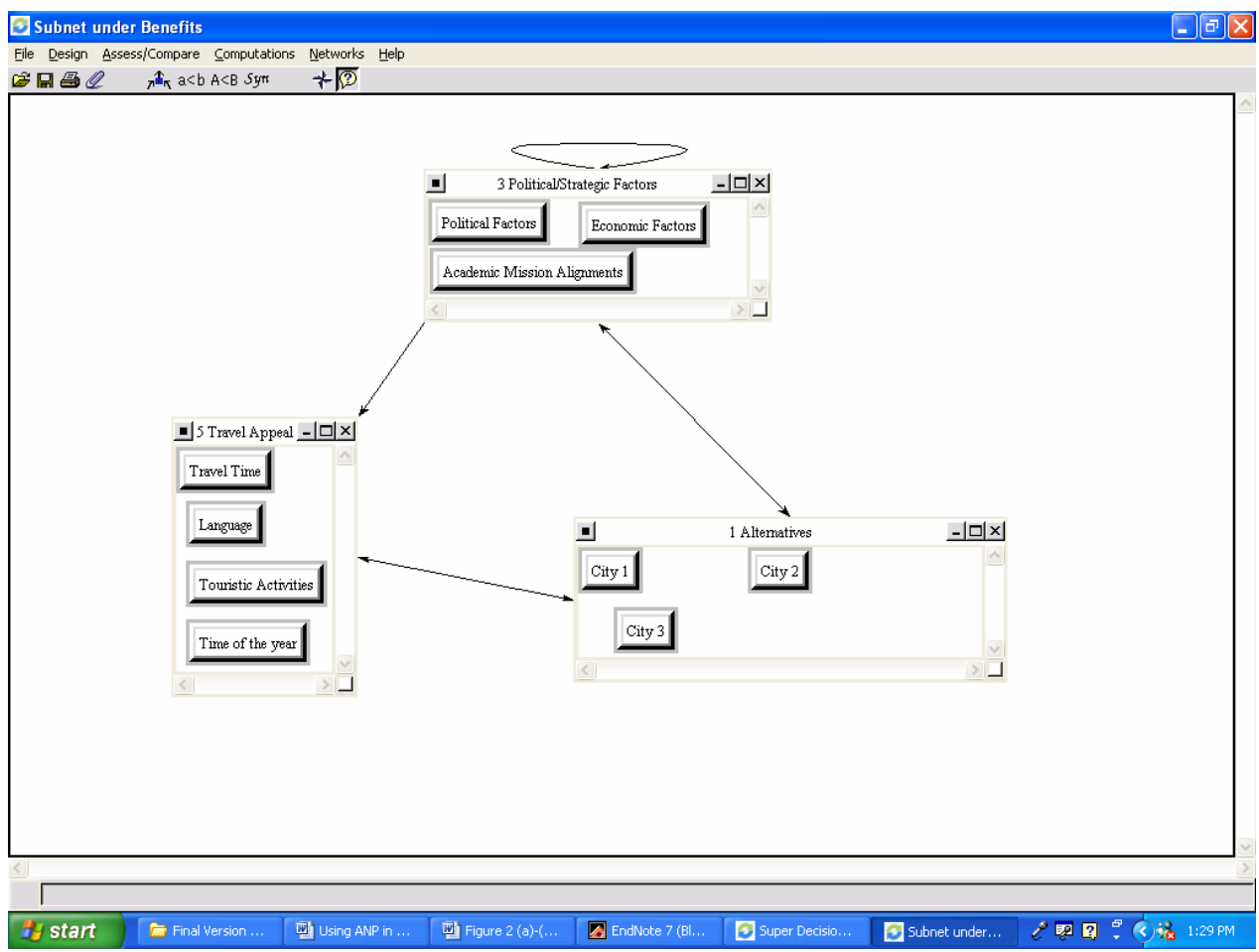

Figure 2 (b) - Benefits Subnet for Conference Site Selection Model 


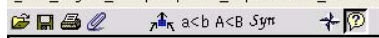
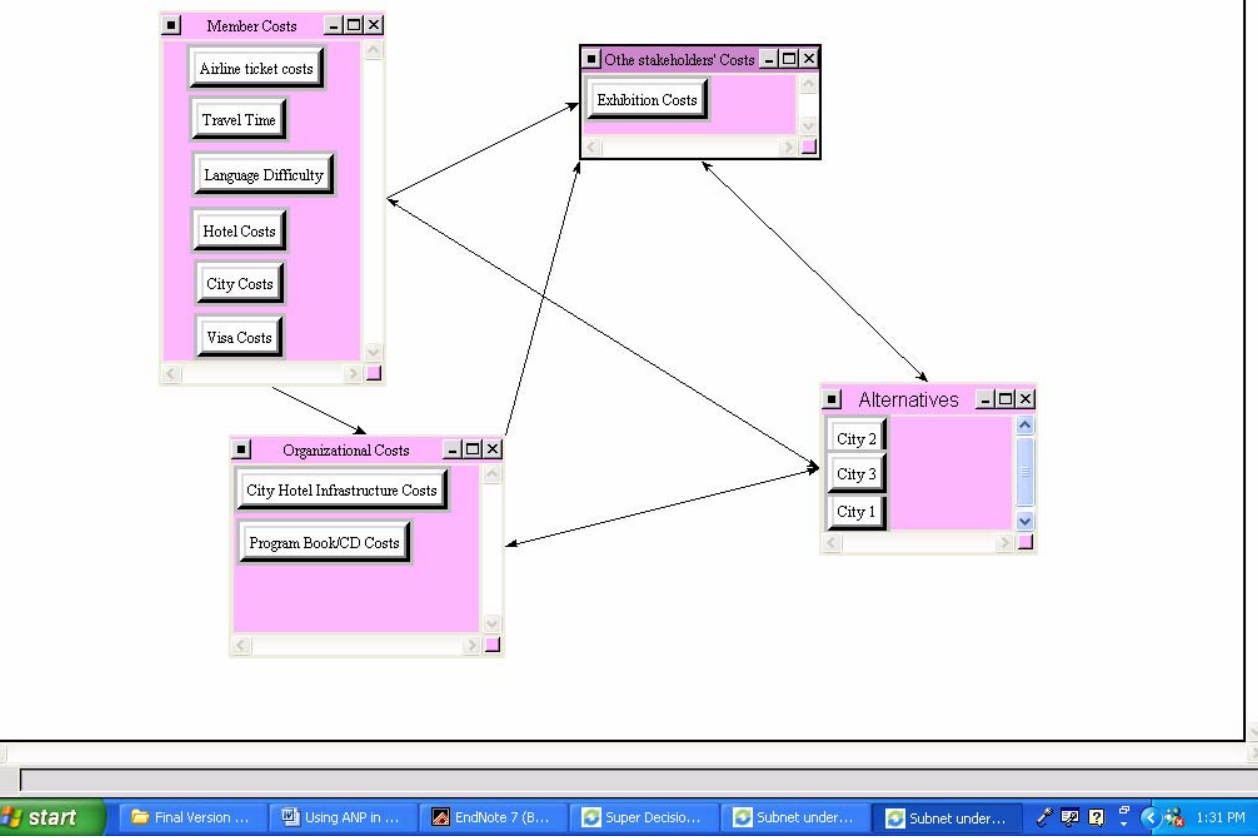

Figure 2 (c) - Cost Subnet for Conference Site Selection Model.

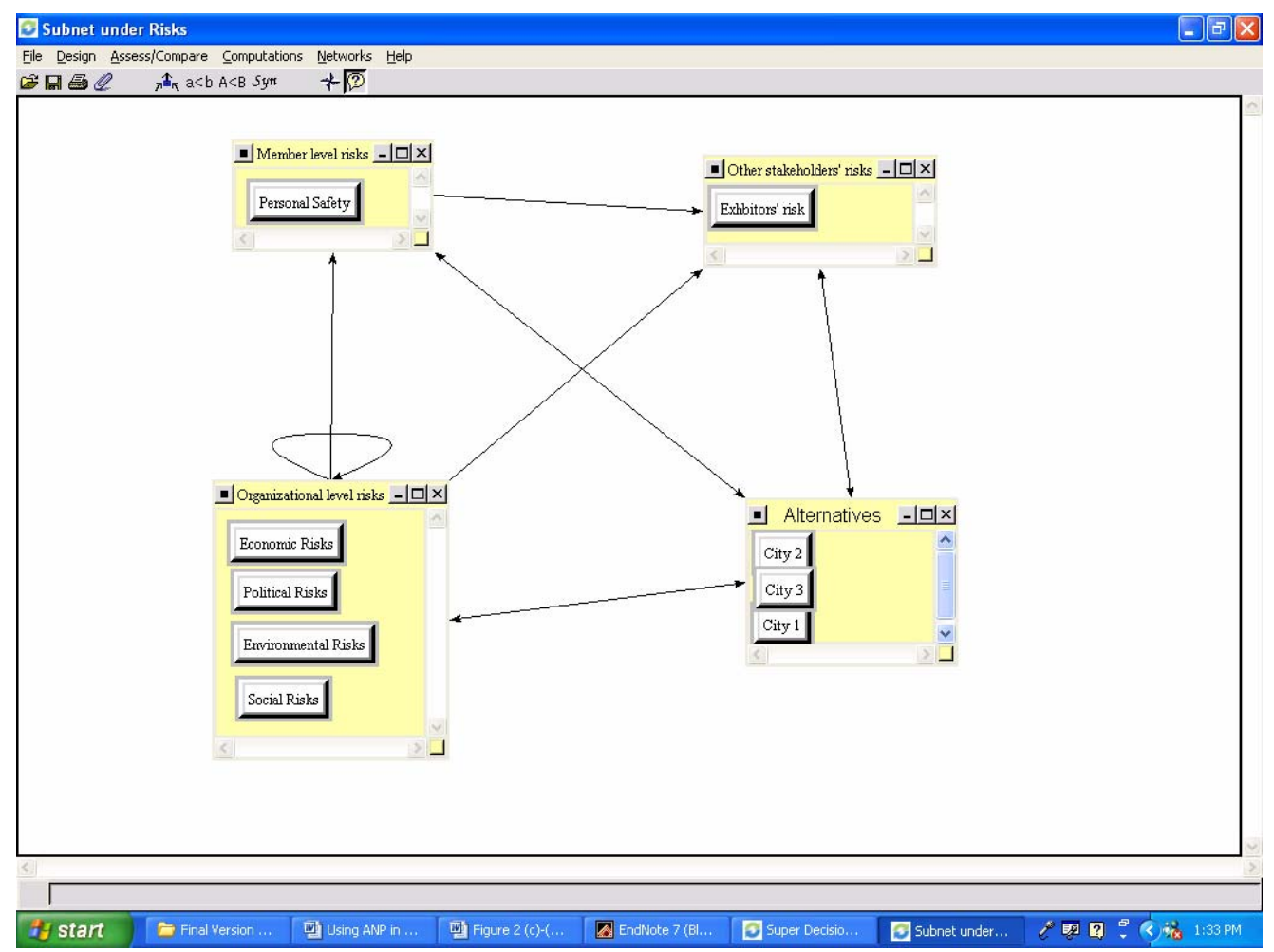

Figure 2 (d) - Risk Subnet for Conference Site Selection Model. 
TABLE 1

Factors for LASA congress attendance and their importance

\begin{tabular}{|c|c|c|c|c|}
\hline Factors & Subfactors & Description & $\begin{array}{l}\text { Normalized } \\
\text { by Cluster } \\
\text { Priority }\end{array}$ & $\begin{array}{c}\text { Limit } \\
\text { Matrix } \\
\text { Priorities }\end{array}$ \\
\hline COSTS & $\begin{array}{l}\text { Airline Ticket Costs } \\
\text { Hotel Costs } \\
\text { Living Costs } \\
\text { Visa Costs }\end{array}$ & $\begin{array}{l}\text { Average ticket price to host country } \\
\text { Average Room Costs per participant } \\
\text { Average per-diem per participant } \\
\text { Associated Time/Complexity/Costs }\end{array}$ & $\begin{array}{r}0.37149 \\
0.4578 \\
0.13447 \\
0.03625\end{array}$ & $\begin{array}{l}0.024792 \\
0.030552 \\
0.008974 \\
0.002419\end{array}$ \\
\hline $\begin{array}{l}\text { TRAVEL } \\
\text { APPEAL }\end{array}$ & $\begin{array}{l}\text { Travel Time } \\
\text { Language } \\
\text { Touristic Activities } \\
\text { Time of the year }\end{array}$ & $\begin{array}{l}\text { Average time to travel to conference } \\
\text { English/Spanish (Spanish preferreed) } \\
\text { Touristic Attractions in the city or nearby } \\
\text { Conferences occur either in March or October }\end{array}$ & $\begin{array}{l}0.04735 \\
0.06889 \\
0.73394 \\
0.14982\end{array}$ & $\begin{array}{l}0.008845 \\
0.012868 \\
0.137098 \\
0.027986\end{array}$ \\
\hline $\begin{array}{l}\text { POLITICAL/ } \\
\text { STRATEGIC }\end{array}$ & $\begin{array}{l}\text { Political Situation } \\
\text { Economic } \\
\text { Academic } \\
\text { Alignment }\end{array}$ & $\begin{array}{l}\text { Some Latin American countries are in upheaval } \\
\text { Economic Instability may affect exchange rates } \\
\text { Whether the city/govt has academic value for LASA }\end{array}$ & $\begin{array}{l}0.25176 \\
0.32285 \\
0.42539 \\
\end{array}$ & $\begin{array}{l}0.007547 \\
0.009678 \\
0.012752 \\
\end{array}$ \\
\hline RISKS & Public Safety Risks & How safe is the city for the visitor & 1 & 0.265345 \\
\hline
\end{tabular}

TABLE 2

Synthesis of Conference Attendance

Priorities

\begin{tabular}{|c|c|c|c|c|}
\hline \multirow{2}{*}{$\begin{array}{c}\text { City } \\
\text { Alternative }\end{array}$} & & \multicolumn{3}{|c|}{ Priorities } \\
\hline & Ideals & & Normals & Raw \\
\hline Dallas & & 0.596934 & 0.264862 & 0.119491 \\
\hline Las Vegas & & 0.656823 & 0.291435 & 0.131479 \\
\hline Puerto Rico & & 1 & 0.443703 & 0.200174 \\
\hline
\end{tabular}


TABLE 3

Comparison of Prediction versus

Actual

\begin{tabular}{|c|c|c|c|c|c|c|}
\hline Year & $\begin{array}{c}\text { City } \\
\text { Alternative }\end{array}$ & $\begin{array}{l}\text { Nominal } \\
\text { Conference } \\
\text { Participation }\end{array}$ & $\begin{array}{r}\text { Actual (1) } \\
\text { Conference } \\
\text { Participation }\end{array}$ & $\begin{array}{c}\text { Predicted } \\
\text { Normalized } \\
\text { Priorities } \\
\end{array}$ & $\begin{array}{c}\text { Predicted } \\
\text { Conference } \\
\text { Participation }\end{array}$ & $\begin{array}{c}\text { Prediction } \\
\text { Error (2) }\end{array}$ \\
\hline 2003 & Dallas & 2818 & 3315 & 0.264862 & 2961 & $-10.7 \%$ \\
\hline 2004 & Las Vegas & 3060 & 3122 & 0.291435 & 3258 & $4.3 \%$ \\
\hline 2006 & Puerto Rico & 5300 & 5300 & 0.443703 & 4960 & $-6.4 \%$ \\
\hline
\end{tabular}

(1) Includes estimated cancellations due to protests over the inminent Irak war.

(2) Calculated as (Predicted-Actual))/Actual

TABLE 4

Normalized Priority Results for each of the Subnets.

\begin{tabular}{|c|c|c|c|c|}
\hline & Beneftis & Costs & Risks & $\begin{array}{c}\text { Normalized } \\
\text { Overall Priority (1) }\end{array}$ \\
\hline City 1 & 0.278134 & 0.631679 & 0.516547 & 0.051549484 \\
\hline City 2 & 0.487189 & 0.186627 & 0.276225 & 0.571526727 \\
\hline City 3 & 0.234677 & 0.181695 & 0.207229 & 0.376923789 \\
\hline
\end{tabular}

Note 1 - Using the multiplicative formula Norm[B/(C*R)] 


\section{APPENDIX}

\section{SAATY COMPATIBILITY INDEX FOR CLOSENESS (HADAMARD PRODUCT)}

3 Alternatives

Actual Market Share

SuperDecisions Estimate

\begin{tabular}{|l|c|c|}
\multicolumn{1}{l}{$\begin{array}{l}\text { Dallas } \\
\text { A1 }\end{array}$} & $\begin{array}{c}\text { Las Vegas } \\
\text { A2 }\end{array}$ & $\begin{array}{c}\text { Puerto Rico } \\
\text { A3 }\end{array}$ \\
28.245 & 26.602 & 45.153 \\
\hline 26.4862 & 29.143 & 44.3703 \\
\hline
\end{tabular}

Pairwise Comparison Matrix from Actual Market Share Data

\begin{tabular}{rrrr}
\multicolumn{1}{c}{ A1 } & \multicolumn{1}{c}{ A2 } & \multicolumn{1}{c}{ A3 } \\
\cline { 2 - 4 } A1 & 1 & 1.06176227 & 0.6255398 \\
A2 & 0.94183041 & 1 & 0.5891524 \\
A3 & 1.59861922 & 1.69735358 & 1
\end{tabular}

Transpose of Comparison Matrix from Estimated Market Share

\begin{tabular}{rrrr}
\multicolumn{1}{c}{ A1 } & \multicolumn{1}{c}{ A2 } & \multicolumn{1}{c}{ A3 } \\
\cline { 2 - 4 } A1 & 1 & 1.10030884 & 1.6752233 \\
A2 & 0.90883574 & 1 & 1.5225028 \\
A3 & 0.59693534 & 0.65681323 & 1
\end{tabular}

Result of Hadamard (Cell-wise) Multiplication of Previous Two Matrices

\begin{tabular}{rrrrrr}
\multicolumn{1}{c}{} & \multicolumn{1}{c}{ A1 } & A2 & \multicolumn{1}{c}{ A3 } & Row Sums \\
\cline { 2 - 4 } A1 & 1 & 1.16826642 & 1.0479189 & 3.216185 \\
A2 & 0.85596914 & 1 & 0.8969863 & 2.752955 \\
A3 & 0.95427231 & 1.11484429 & 1 & 3.069117 \\
& & & \multicolumn{2}{c}{ SUM } & 9.038257
\end{tabular}

Number of Alternatives: $\mathrm{N}$

Compatibility Index $=\quad\left(\mathrm{SUM} / \mathrm{N}^{\star \star} 2\right)=\quad 1.00425081$

A compatibility index of less than 1.1 is considered to be good! 
Garuti, C. and M. Escudey, Eds. (2005). Toma de Decisiones en Escenarios Complejos. Santiago de Chile, Chile, Editorial Universidad de Santiago.

Meade, L. and A. Preseley (2002). "R\&D Project Selection Using the Analytic Process." IEEE Transactions on Engineering Management 49: 59-66.

Saaty, T. L. (1990). Multicriteria Decision Making -The Analytic Hierarchy Process. Pittsburgh, PA., RWS Publications.

Saaty, T. L. (2000). Fundamentals of Decision Making with the Analytic Hierarchy Process. Pittsburgh, PA., RWS Publications.

Saaty, T. L. (2001). Decision Making with Dependence and Feedback: The Analytic Network Process. Pittsburgh, PA., RWS Publications.

Saaty, T. L. (2004). Super Decisions Software. Pittsburgh, RWS Publications.

Sarkis, J. and R. Sanadarraj (2002). "Hub location at digital equipment corporation: A comprehensive analysis of qualitative and quantitative factors." European Journal of Operations Research 137(2): 336.

Shang, j. S., Y. Tjader and Y. Ding (2004). "A Unified Framework for Multicriteria Evaluation of Transportation Projects." IEEE Transactions of Engineering Management 51(3). 